\title{
Regulations and Measurement of Human Capital Resources: The Impact of MLC in the Seafarers Control and Management Systems
}

\author{
Di Vaio Assunta ${ }^{1, *}$, Varriale Luisa ${ }^{2}$, Alvino Federico ${ }^{1}$ \\ ${ }^{1}$ Department of Law, University of Naples "Parthenope", Naples, Italy \\ ${ }^{2}$ Department of Sport Science and Wellness, University of Naples "Parthenope", Naples, Italy
}

Email address:

susy.divaio@uniparthenope.it (A. Di Vaio), luisa.varriale@uniparthenope.it (L. Varriale), alvino@uniparthenope.it (F. Alvino)

\section{To cite this article:}

Di Vaio Assunta, Varriale Luisa, Alvino Federico. Regulations and Measurement of Human Capital Resources: The Impact of MLC in the Seafarers Control and Management Systems. Journal of Human Resource Management. Special Issue: Challenges and Opportunities in the Performance Measurement and Control Systems of Human Resources Management for the Services Industry.

Vol. 3, No. 2-1, 2015, pp. 20-27. doi: 10.11648/j.jhrm.s.2015030201.13

\begin{abstract}
This paper aims to verify the role of the managerial control systems in the measurement of the factors that may have a negative impact on the job performance of the human resources working on board ships. More specifically, we investigate the main causes, such as social isolation, boredom, fatigue, lack of social recognition, conflicts among the member of the crews and so on, affecting the efficiency and effectiveness of the seafarers' job on board and consequently the performance of the ships. In the last years the international regulation about the work on board ships is becoming over more relevant in order to ensure the best security and welfare conditions of the workers and, more in general, of the maritime crews. In addition to the international conventions SOLAS (Safety of Life at Sea) and STCW (Standards of Training, Certification and Watch keeping for Seafarers), in 2006 it has been introduced the Maritime Labour Convention (MLC) no. 186, adopted in Geneva on $23^{\text {rd }}$ Feb by the $94^{0}$ session, it introduced into force on Aug $20^{\text {th }}$ 2013. This Convention establishes several rules in order to ensure the acceptability between governments, ship owners and seafarers about the principles of safe and healthy work fixed in the Titles. This study, within a wider research project, aims to analyze, through a qualitative approach, on one side, the impact of the MLC on the Italian legislative context, and, on the other side, the fatigue factor in the managerial control and human resources literature. Therefore, this study focuses on the Title "health protection, medical care, welfare and social security" indicated by MLC, and thanks to the support of some shipping companies, it supplies a set of key performance indicators to measure the fatigue causes. Finally, this paper provides interesting insights on the managerial control system adoptable by the shipping companies in the recognition of the MLC.
\end{abstract}

Keywords: Maritime Labour Convention, Fatigue, Managerial Control Systems

\section{Introduction}

In the recent years the issue of the workers' security on board ships is becoming more and more significant overall because the international regulation, the European laws and the national regulations have introduced a rigid rules system on the "health protection, medical care, welfare and social security protection".

The main goal of the Maritime Labour Convention in 2006 (MLC, 2006) is to ensure more favourable conditions for the workers on board ships, called seafarers, that is any person who is employed or engaged or works in any capacity on board ships to which the Convention is applied.
Besides, the Convention applies to all ships, whether publicly or privately owned, ordinarily engaged in commercial activities, other than ships engaged in fishing or in similar pursuits and ships of traditional build such as dhows and junks. This Convention does not apply to warships or naval auxiliaries. It sets several rules to ensure the acceptability between governments, shipowners and seafarers about the principles of dignified work. According to the Article I of the Convention, each State Member (Member), which ratifies the Convention, undertakes to give complete effect to its provisions in order to secure the rights of all 
seafarers to decent employment. In addition, Members shall cooperate with each other for ensuring the effective implementation and enforcement of the Convention [1].

The Regulations and the Code included by MLC are articulated into general areas under five Titles.

In the five Titles it is possible to observe that the legislative framework requires to the Members the ratification of the MLC mainly to guarantee the health protection and the professional dignity to all seafarers. Among the factors that threaten these conditions the fatigue factor plays a crucial role. The fatigue seems to be the main cause of inefficiency and ineffectiveness of the work activities on board ships. Indeed, the Convention dedicates a specific regulation about this aspect, entitled the working hours and resting hours (Regulation 2.3-MLC, 2006), that aims to ensure the specific regulatory of seafarers' hours of work and hours of rest.

From the point of view of the shipping companies, it is necessary that for each seafarer the companies ensure an equal distribution of tasks among workers, because the fatigue may have a negative impact on the seafarers' performance. Indeed, the fatigue makes the worker more irritable and more prone to conflict with other seafarers, but also less motivated and less liable to the operational process in which he/she is involved. For instance, the carrying out of a task assigned to the seafarer requires, in normal conditions, the use of one hour time. The fatigue factor might increase the time required to carry out the same task. The increase, in working time required to carry out the task, implies (a) an increase in costs (e.g. overtime); (b) the output of the process than the one planned; (c) or both. The "performance under fatigue" impacts on mental and physical health of the seafarers and, therefore, it is relevant to ensure safety to the same committee functions, that operational processes.

On the other hand, the factors that affect on the seafarers' health become the costs for the social security system and for which insurance coverage is provided by the specific institutions. In determining the national standards, each Member shall take account of the danger posed by the fatigue of seafarers, especially those whose duties involve navigational safety and the safe and secure operation of the ship. We observe that in the Italian legislative context the MLC has been ratified on September $13^{\text {th }}, 2013$; regarding the assurance Institute, it was carried out until 2010 by IPSEMA (Insurance Institute for the Maritime Sector), whose functions with the Law July 30, 2010 no. 122 conversion with amendments of Decree 78/2010 have been attributed to another Institute called INAIL (National Institute for Insurance against Accidents at Work).

However, in this legislation framework briefly described we have observed that the regulations, standards and codes do not specify the tools to identify the causes of the fatigue factor. In this direction, each shipping company could adopt several ways to limit the impact of this factor on the processes carried out on board ships. Considering that the effects of the fatigue, such as the illness status of the seafarers is transferred to economics third parties (e.g. accident insurance institutions), we aim to identify some tools in the managerial control systems that may support the management of the fatigue factor. Using a qualitative approach, this explorative study is focused on the analyze of the following aspects: the management and accounting literature on the specific issue, and MLC and legislation in a specific context, like the Italian market. Also, we gathered interesting information and insights through semi-structured interviews conducted in some shipping companies.

The paper is structured as follows: section 2 is focused on the analysis of the fatigue factor laid down by MLC, while the subsection 3 shows the peculiarities of this topic in the Italian legislative framework. Section 4 evidences the main contributions in the literature on the fatigue factor in the maritime industry. Section 5 describes the methodology used in this study; the section 6 supported by literature on the management control evidences some key performance indicators for the control and measurement of the fatigue for several categories of seafarers. Finally, section 7 outlines some final considerations.

\section{The Fatigue Factor in the Maritime Labour Convention}

The national legislation of each Member has to ensure the respect of the rights established by the Convention. However, for each disposition in MLC there are some "amendments" and rules that support the Member in adopting the same Convention. More specifically, the Convention introduces also some "explanatory note" to the Regulations and Code in order to better explain its subject. However, the explanatory notes do not form part of the MLC. The Convention is structured in the following three parts: Articles, Regulations and Code. The Articles and Regulations are a firm set of rights and principles and the basic obligations of Members ratifying the Convention, while the Code includes the details for the implementation of the Regulations. The Code is composed by two Parts, A and B. Regarding the Part A the regulations and the provisions are mandatory (called mandatory Standards), while concerning the Part B they are not mandatory (called non-mandatory Guidelines).

The MLC arranges the Regulations and the Code into general areas under five Titles, such as:

1. minimum requirements for seafarers to work on a ship;

2. conditions of employment;

3. accommodation, recreational facilities, food and catering;

4. health protection, medical care, welfare and social security protection;

5. compliance and enforcement.

Each Title contains groups of provisions relating to a particular right or principle, with connected numbering. For example, the first group in Title 1, consists of Regulation 1.1, Standard A1.1 and Guideline B1.1, relating to minimum age.

Reading the five Titles it is possible to observe that the legislation framework requires to the Members ratified the MLC to mainly guarantee the health protection and the 
professional dignity to all seafarers.

The purposes of the international legislation indicated by the MLC allow specifying the seafarers' rights on board ships regarding the status or dignity of the worker, but also the working environment, both in terms of comfort and cleaning and order among members of the crews of different ethnicity and nationality.

In details, according to the Article IV [1] the social right of the seafarers employment on ships board is established. More in details, the safe and secure workplace is considered a right for the seafarer; in fact, each seafarer has the right to obtain specific terms of employment, such as decent working and living conditions on board ship and each member has the right to health protection, medical care, welfare measures and other forms of social protection. In order to ensure these rights the Convention also regulates the hours of work for the seafarers. Indeed, the Regulation 2.3 - Hours of work and hours of rest aims to guarantee that seafarers have to require and respect hours of work or hours of rest. In this direction, each Member shall ensure that the working hours and resting hours for seafarers are regulated. Therefore, it shall establish maximum hours of work or minimum hours of rest over given periods that are consistent with the provisions in the Code. According to the Standard A2.3 - Hours of work and hours of rest included in the same Convention, the limits on hours of work or rest shall be as follows [1]:

(a) maximum hours of work shall not exceed:

- 14 hours in any 24-hour period

- 72 hours in any seven-day period

or

(b) minimum hours of rest shall not be less than:

- 10 hours in any 24-hour period

- 77 hours in any seven-day period

Resting hours may be divided into no more than two periods, one of which shall be at least six hours in length, and the interval between consecutive periods of rest shall not exceed 14 hours. Besides, according to the Convention each Member shall require the posting, in an easily accessible place, of a table with the board ship working arrangements, which shall contain for every position at least [1]:

a) the schedule of service during the navigation at sea and service in port

b) the maximum hours of work or the minimum hours of rest required by the national laws or regulations or applicable collective agreements

Each Member shall require that records of seafarers' daily hours of work or of their daily hours of rest be maintained to allow monitoring of compliance with paragraphs 5 to 11 inclusive of this Standard. The records shall be in a standardized format established by the competent authority taking into account any available guidelines of the International Labour Organization (ILO) or they shall be in any standard format prepared by the same organization. They shall be in the languages required by the paragraph 11 of this Standard [1].

The seafarers shall receive a copy of the records pertaining to them which shall be endorsed by the master, or a person authorized by the master, and by the seafarers.
The Guidelines include the conditions that the shipowners (called shipowners' liability), and more in general, the shipping companies shall follow in order to guarantee the security on board ships.

In this direction, the Guideline B4.3 on "health and safety protection and accident prevention" and, more in detail, according to the Guideline B4.3.1 - Provisions on occupational accidents, injuries and diseases - the competent authority should guarantee that the national guidelines for the management of occupational safety and health address several topics [1:62]:

- general and basic provisions

- structural features of the ship, including means of access and asbestos-related risks

- $[\ldots \ldots]$

- the effects of noise in the workplace and in shipboard accommodation

- the effects of vibration in the workplace and in shipboard accommodation

- $[\ldots \ldots]$

- physical and mental effects of fatigue

- $[\ldots \ldots]$

The assessment of risks and reduction of exposure on the matters referred should take account of the physical occupational health effects, including manual handling of loads, the noise and vibration, the chemical and biological occupational health effects, the mental occupational health effects, the physical and mental health effects of fatigue, and the occupational accidents. The necessary measures should consider the preventive principle according to which, among other things, by combating risk at the source, adapting work to the individual, especially as regards the design of workplaces, and replacing the dangerous by the non dangerous or the less dangerous, and to have precedence over personal protective equipment for seafarers [1].

\section{The Fatigue Factor in the Italian Seafarers Regulations}

The acknowledgment of MLC may be achieved through the national laws or regulations, or through other measures unless specified otherwise in the Convention.

In Italy the Convention has been ratified on September $13^{\text {th }}$ 2013. The Italian regulations on health and security of the seafarers are mainly based on the Legislative Decree on July $27^{\text {th }} 1999$ no. 271. "Adaptation of the legislation on the health and safety of seafarers on board of the national merchant ships and fishing, under the Law $31^{\text {st }}$ December 1998 no. 485" [2].

In order to guarantee health and security of the seafarers on board ships, this Decree identifies the criteria for the hygiene of housing for the crews, it determines the obligations and liabilities for shipowners, seafarers and other interested persons in relation to the risk assessment on board ship; it identifies the criteria for the organization of the health care and safety system about the work on board, it defines the duration of working and resting time of seafarers, it ensures 
information and training of crews and so on.

This Decree establishes specific conditions, such as [2]:

(a) evaluation of the risk situations of health and safety, connected with the performance of work on board;

(b) elimination of risks for using materials harmful to the health of the worker

(c) risk reduction (at source)

$[\ldots \ldots]$

In this direction, the main aims of the Legislative Decree no. 271/1999 are[2]:

- assessment, reduction and elimination of health risks

- security environment and work activities

- prevention planning

- information, training, consultation and participation of workers on the prevention

- education for workers adapted to their work

The Article no. 6 identifies the obligations for the shipowner and the commander. In particular, the shipowner has to evaluate the risks for the health and security of the seafarers. A front of these liability, the Legislative Decree establishes two main tools that support the shipowner in the risks evaluation processes: the security plan of the work environment on board ships and the technical report on the assessment on the risks system on board.

In order to assess, reduce and eliminate the health and security risks on board ships the Italian regulation includes an Annex to the Legislative Decree no. 271/1999. More specifically, it is the Annex no. 1 that aims to provide a general description of "fatigue factor" for identifying the work activities on board ships that can contribute to fatigue and classify these factors into categories specifying the point at which factors may be related. The purpose of this document is to increase the awareness of those who carry out maritime activities of the relevance of these factors. The knowledge will enable a greater awareness in adopting operational decisions. According to the law, the fatigue is defined by the Annex no. 1 as the factor that decreases the human performance slowing the reflexes physical and mental and/or reducing the ability to make rational assessments. Fatigue can be caused by factors such as prolonged periods of physical and mental activities, inadequate rest, adverse environmental conditions, physiological factors and/or stress or other psychological factors. Annex 1 evidences the main causes of the most recognized and documented factors, such as [2]:

(a) poor quality of rest

(b) excessive workloads

(c) excessive noise

(d) interpersonal relationships

There are many causes of fatigue that according to Annex no. 1 can be grouped relatively to the activities carried on ship board. Among these activities, it is possible to identify the following four groups that include the causes of the fatigue [2]:

- management ashore and on ship board and responsibilities of Directors (scheduling of work on board ships and rest times, assigning tasks, scheduling of routes, port operations, and so on)

- ship factors (the level of ship automation, reliability of equipment on board ships, levels of noise, heat and vibration, quality of life and work on board ships, features and load requirements, and so on)

- crew factors (completeness of training, experience, quality and competence of the crew, compatibility in the composition of the crew)

- external environmental factors (weather and ice conditions, efficiency and effectiveness of seaport, maritime traffic density)

Besides, according to the Annex no. 1 it is necessary that the management of the shipping companies and, more specifically, the technical management or department of the companies provide to the crews the guidelines about the operating standards of the ships, the time of the routes, the destinations, the communication processes on board ships and between the ships and departments ashore. Furthermore, the technical management has to identify the causes of the conflicts among the seafarers that consist in multicultural crews on the ship board. This department has to check the increased workload when the crew is reduced.

The fatigue that characterizes the quality of "ship life" may be influenced by the boredom. Therefore, the technical management, along with the human resource department of the shipping company, should provide stimulus to the seafarers. Finally, the technical management should recognize the external environmental factors that contribute to the fatigue.

The assessment of the health and security risks system that involves the seafarers is the first step for planning the prevention on board ships. The identification of the causes threatening the health and security of the crews is a critical factor for the success or not in the adoption of the Legislative Decree no. 271/1999 and the Regulation 2.3 [1]. In particular, it is possible to observe that the Italian legislation requires to the shipowner the security planning of the work environment and the technical report on the assessment of the risks on board ships, but it does not suggest specific tools or methods to obtain an effective health and security risks system. Indeed, the terms "assessment, risks, forecasts" related to the human capital resources imply the measurement and control of the resources in order to evaluate the performance. Moreover, it is also needed to clarify the concept of risk, which in the business administration literature is associated to a negative change between what it was planned and what it has been achieved. With reference to this negative variance, it is necessary to identify the causes of the variation [3].

We observe that both Italian legislation represented mainly by the Legislative Degree no. 271/1999 and MLC identify the fatigue as the critical factor for the health and security of seafarers forcing the shipowners to adopt a set of procedures to reduce the risks on board ships. On the other side, we observe that have not been specified tools to allow giving substance to the security plan of the work environment on board ships and to the technical report. 


\section{The Fatigue Factor in the Human Resources Management on Board Ships}

Most scholars connect the numerous maritime accidents to human error $[4,5,6,7,8,9]$, in fact, in spite of the advances in technology, in the shipping industry about $80 \%$ of maritime accidents is attributable to the human error [9]. In the majority of these cases the fatigue has consistently been identified as the main contributory linked to the accident events. Consequently, research pays an increasing attention to the causes and incidence of fatigue in seafarers.

In the scenario very complex, also for the globalization of the shipping industry, we mainly focus on fatigue factor in order to identify and develop effective tools to measure it and its negative effects on the crew performance. Numerous authors argue that long working hours and not comfortable work conditions often cause fatigue, also, some phenomena, like social isolation, drug abuse, and psychiatric disorders, are very common in the shipping workplace $[10,11,12,13,14,15$, 16, 17].

Fatigue represents a very complex and critical issue in the shipping industry, where personal and environmental factors can significantly and negatively affect the seafarers' performance increasing their level of fatigue and stress. Fatigue is not a new issue in the maritime domain, in fact, researchers have paid an increasing attention to this topic in the last decades trying to identify and investigate its causes, like the lack of sleep or inadequate work conditions, and proactive policies in areas as employment practices, manning levels, shipboard ergonomics, shiftwork patterns and the training in the fatigue management [9]. Some scholars have outlined that numerous disastrous outcomes derive from fatigue in terms of poor health and also diminished performance [18]. However, the seafarers tend to require better conditions at workplace and, at the same time, the need to improve work conditions, in order to enhance consequently the seafarers' performance, is significantly increasing for the organisations.

Some authors have evidenced, as already said, that many marine accidents could be attributable to fatigue [19]. The National Transportation Safety Board [20], attempting to address the operator fatigue, has reported that seafarers were identified out of the occupational groups included to have the second highest number of maximum work hours in a 30 -day period, behind rail operators. A survey study of 1,000 officers by the National Union of Marine Aviation and Shipping Transport Officers (NUMAST, 1995, as reported by [21]) has shown that $77 \%$ of individuals felt that fatigue has significantly risen in the past 3-10 years, instead $84 \%$ felt that stress was also more prevalent. A further study of 563 seafarers has shown that $50 \%$ of individuals worked more than 85 hours in a week and $66 \%$ felt that extra manning was necessary to reduce fatigue (NUMAST study reported in [21]). Another cause of high level of fatigue for seafarers has been recognized in a poor sleep [22].

Previous studies focused on this topic have identified exposure factors to predict factors: "working hours, sleep problems, high levels of vibrations and noise, tour length (longer tours equate to less fatigue), shift length, job demands, stress at work, and standing watch" [23: 404].

Several studies conducted in Europe and United States have outlined that fatigue among seafarers working is widespread, by providing interesting aspect to debate on which regulations have been drafted. It is not easy to investigate the causes and effects of fatigue in the shipping industry because of the variation world-wide in ship types, trades, manning levels and living conditions on board ship, also the different national rules and so on.

In the prevalent literature different approaches have been used in order to measure fatigue and analyze the impact of patterns. We can observe the adoption of the following approaches: self-report measures [24], measures of physiological processes, a combination of physiological, behavioural and self-report measures [25].

The main cause identified for fatigue of seafarers is related to the sleep patterns, that is the quality and quantity of sleep [25]. More specifically some authors have identified some key features related to fatigue that impact on the quality and quantity of sleep, such as fragmented (and therefore poorer quality) sleep, having to sleep at physiologically inappropriate times, insufficient breaks for resting between shifts, long work days, and so on [26]. Because of the difficulty to measure and analyze the fatigue factor by identifying its causes and main effects, in this study we aim to consider this pattern in order to investigate and develop tools addressed to exam seafarers' fatigue by evidencing its impact on their performance and so consider effective tools to prevent and manage fatigue in perspective of high level of performance. In the international and national regulations on human resource management in the shipping industry, and especially fatigue factor, although there are many relevant aspects that are useful to define fatigue and the related stress, still there are no information or suggestions about policies and tools to prevent and manage the phenomenon.

\section{Metodology}

We used the case study methodology interviewing three shipping companies located in Italy. In this explorative study we conducted 6 face-to-face semi-structured interviews to key actors with managerial role and functions in three shipping companies. We interviewed the technical managers (3) and the accounting managers (3) of these shipping companies that are specialized in the carriage of passengers and goods. The interviews have been based mainly on the following aspects investigated: the tasks of the seafarers on board ships, the time of the routes, the technical characteristics of the ships, the resting hours, the average time to performance of the processes on board ships, and finally the number of accidents, injuries and illness of seafarers. 


\section{Measurement, Control and Assessment of the Fatigue Factor}

In the legislative framework, briefly defined above, we have evidenced that to ensure the health and security of the seafarers on board ships, the shipowners, and more in general the shipping companies, should adopt systems of prevention, reduction and risks assessment. In other words, in order to identify all the factors that threaten the health and safety, the shipping companies should organise their control systems which are not necessarily based on financial measures. Indeed, "although management control systems have financial underpinnings, it does not follow that money is the only basis of measurement, or even that it is the most important basis. Other quantitative measurements, such as $[\ldots]$ productivity measures, tonnage of output, and so on, are useful" [27: 42]. Among these factors there is the fatigue; it is caused by many factors, both exogenous and endogenous. In order to respond to the legislation in force since 1999 and the Convention ratified in 2013, companies can identify a system of indicators that allows the identification of the cause of fatigue, the monitoring and measuring of the impact on the performance of seafarers activities carried out on board ships.

The factor "fatigue" indicated by the regulations does not appear clearly quantifiable. Indeed, the term "excess" to the workload and the noise, or even "poor quality" refer to the rest of seafarers, and "relationships" are not useful to support the information system of shipping companies.

Thus, when the unfavorable event occurs due to the "fatigue factor", you have to face a scenario characterized, first, by the legislation that aims "protecting" the human resource and, second, by the shipping companies, which have to intervene in terms of protection from risks. In this direction, the cost to the company should not be reduced to the amount of damages, but to the costs related to the causes of the fatigue factor.

In order to measure the fatigue causes, included in the four groups (Management ashore and on ship board and responsibilities of Directors, Ship factors, Crew factors, External environmental factors) following the Annex no. 1 and supported by the main contributions in the management accounting literature, it is possible to identify some key indicators.

The accounting literature (Human Resources Accounting) draws from the studies on the human organisation conducted by Likert [28]. According to the author, the judgments on the efficiency and effectiveness of the processes are linked to the human organisation quality in the companies. In an wider concept of human capital, that not always it is accepted by the Human Resource Accounting (HRA), people are resources that have a value, therefore, they are considered as intangible assets.

In this direction, in order to measure the contribute of these intangibles, it is possible to suppose a scheme that allows relating the role on board ship of the seafarer and his/her competences through the drivers or key performance indicators [29]. Then, the results of the indicators may be interpreted together with single operating processes carried out on board and, as well as, with ship performances. Therefore, a set of key performance indicators [30] has to consider one of four groups that includes the role on board ship of the seafarer, tasks and causes of the fatigue factor.

In table no. 1 we indicate the relationship between causes of the fatigue factor, the role of the seafarers on board ship, the tasks and the key performance indicators. These key performance indicators are testing in some shipping companies that have cooperated to this explorative study. In this direction, we explain how to identify the indicators that in a management control systems of the shipping companies can support the measurement and control activities adopting the MLC and the national legislation, such as the Italian regulation (Legislative Degree no. 271/1999, Annex no. 1). For instance, the purpose of the shipping company or better of its technical department is to monitor the workload of some categories of seafarers on specific ship of the fleet.

Table 1. KPI in the management ashore and on board the ship and responsibilities of directors

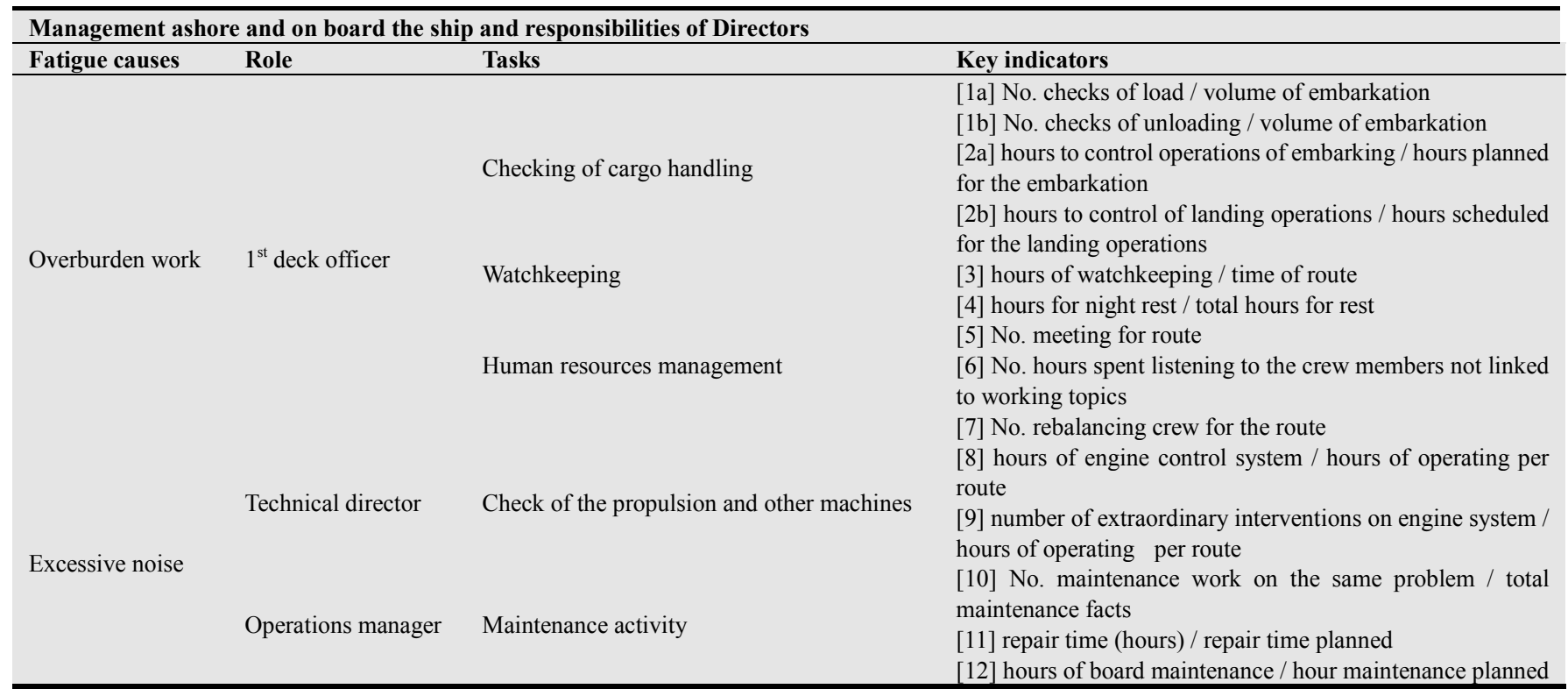


The department recognizes the maritime activity group indicated by Annex no. 1, as well as "management ashore and on board the ship and responsibilities of Directors".

Then, in a second step, the department identifies a seafarer like as a deck officer, who is a vital member of the ship management team. The aim of the shipping company, and more specifically of the technical department, is to identify, investigate and monitor the main causes of the workload for this professional figure selected. For example, it is possible to identify the causes of the fatigue factor regarding the figure of the deck officer. In details, the technical department wants to monitor the weight of this factor in the relationships that the deck officer established with other seafarers on board ship. The activities group monitored is "Management ashore and on board the ship and responsibilities of Directors" (Annex no. 1), that includes "scheduling of work on board ships and rest times". The task identified for this worker is the "human resource management", therefore, in order to realize an effectiveness scheduling of work on board ships and rest times, the management control system of the shipping company can include the following key indicators:

[4] No. hours for night rest/total hours of rest;

[5] No. meetings for route

[6] No. hours spent listening to the crew members not linked to working topics

[7] No. rebalancing crew for the route (e.g. work teams)

Concerning the maintenance activity by other figures on board ship, like as the technical director and the operating manager, it is possible to identify the following key performance indicators (table no. 1):

[10] No. maintenance work on the same problem/total maintenance facts

[11] Repair time (hours)/repair time planned

[12] No. hours of board maintenance/no. hours maintenance planned.

These indexes measure the effectiveness and efficiency of the ships, and more in details of the work team on board.

These drivers could be integrated with others indexes regarding the production, such as:

[13] No. hours of ship stopping (for maintenance, breakdown, and so on)/hours of sailing

[14] No. hours of sailing for route/no. hour sailing planned

The index no. [13] measures the weight of the ship stopping on the total hours of sailing; while the index no. [14] evidences if the ship maintains its rated speed.

These indicators represent a first step to identify a map of key performance indicators for each ship. For example, the boredom is another cause of the fatigue factor. This cause is very critical above all for the passengers transport, such as cruises and ferries. Because the seafarers operating in front office, this factor can pour this negative cause in the relationships with the passengers. Among the causes of the boredom could be the multi-cultural crew. Also in this case, it is possible to identify some key indicators proposed to support the operations management in order to ensure the security on board ships.
In this way the shipping companies improve their management measurement and control systems and they could give substance to the security plan of the work environment on board ships and a technical report of the assessment on the risks system on board.

\section{Final Considerations}

We have focused our short notes on the legislative framework of MLC on the fatigue factor. More in details, we have observed the main obligations and liabilities that MLC establishes for shipowners and Members. Among the members, we analysed the regulatory context in Italy where the main Law on protection and security of the seafarers is identifiable in the Legislative Degree no. 271/1999 and its Annex no. 1. This means that the ratification of the Convention by Italy in 2013 is a regulatory context already well-prepared. However, in order to guarantee health protection, medical care, welfare and social security of the seafarers on board ships, both regulations do not suggest to the shipowners the management tools to give substance to the technical report of the assessment on the risks system on board. Considering this lack, our study is focused on the identification of the causes of the specific fatigue factor, that undermines the conditions that the Convention and the Legislative Decree require to the shipowners.

Thanks to the support of the management control literature and to some technical managers of shipping companies, we have identified some key performance indicators.

These indexes allow us to know, to monitor and to check the causes of the fatigue. In this way, the technical management can schedule the work activities for each ship reducing the exposure to fatigue of seafarers on board ships.

These final considerations represent the first step of the study and they are not extended to all shipping companies of the Member selected in our analysis. In the next step, we aim to develop further significant key performance indicators that will be based on nature of traffic (passengers and cargo). In addition, we will try to consider more factors that threaten the health and security of the seafarers on board ships.

\section{Acknowledgements}

The authors are grateful for the contributions of the operators interviewed. Any errors are entirely attributed to the authors.

\section{References}

[1] Maritime Labour Convention. 2006.

[2] Legislative Decree no. 271/1999, Annex no. 1

[3] Sassi S. Il sistema dei rischi di impresa. Vallardi, Milano. 1940.

[4] Hetherington, C., Flin, R., and Mearns, K. "Safety in shipping: The human element". Journal of safety research, 37(4), 2006, pp. 401-411. 
[5] Darbra, R.M., and Casal, J. "Historical analysis of accidents in seaports". Safety Science, 42, 2004, pp. 85-98.

[6] Grech, M., Horberry, T., and Smith, A. "Human error in maritime operations: Analyses of accident reports using the leximancer tool". Paper presented at the Proceedings of the 4th Annual Meeting of the Human Factors and Ergonomics Society, Baltimore, U.S. 2002.

[7] Hansen, H.L., Nielsen, D., and Frydenberg, M. "Occupational accidents aboard merchant ships". Occupational \& Environmental Medicine, 59(2), 2002, pp. 85-91.

[8] Griffin, M. A., and Neal, A. "Perceptions of safety at work: A framework for linking safety climate to safety performance, knowledge and motivation". Journal of Occupational Health Psychology, 5(3), 2000, pp. 347-358.

[9] Reyner, L., \& Baulk, S. Fatigue in ferry crews: a pilot study (p. 34). Cardiff: Seafarers International Research Centre. 1998.

[10] Allianz. Safety and Shipping 1912-2012 From Titanic to Costa Concordia. Hamburg: Allianz Global Corporate \& Specialty, 2012.

[11] Horck, J. Getting the best from multi-cultural manning. Paper presented at the BIMCO 100 years and GA, Copenhagen, Denmark. 2005.

[12] Kahveci, E., Lane, T., \& Sampson, H. Transnational seafarer communities: Seafarers International Research Centre, Cardiff University. 2002.

[13] Lützhöft, M., Grech, M. R., \& Porathe, T. Information Environment, Fatigue, and Culture in the Maritime Domain. Reviews of Human Factors and Ergonomics, 7(1), 2011, pp. 280-322. doi: $10.1177 / 1557234 \times 11410391$

[14] Progoulaki, M., \& Roe, M. Dealing with multicultural human resources in a socially responsible manner: a focus on the maritime industry. WMU Journal of Maritime Affairs, 10(1), 2011, pp. 7-23. doi: 10.1007/s13437-011-0003-0

[15] Sampson, H. International seafarers and transnationalism in the twenty-first century. Manchester, UK: Manchester University Press. 2013.

[16] Sampson, H., \& Thomas, M. Lone Researchers at Sea: Gender, Risk and Responsibility. Qualitative Research, 3(2), 2003a, 165-189. doi: 10.1177/14687941030032002

[17] Sampson, H., \& Thomas, M. The social isolation of seafarers: causes, effects, and remedies. International maritime health, 54(1-4), 2003b, pp. 58-67.

[18] Josten, E.J.C., Ng-A-Tham, J.E.E., and Thierry, H. "The effects of extended workdays on fatigue, health, performance and satisfaction in nursing". Journal of Advanced Nursing, 44(6), 2003, pp. 643-652.

[19] Raby, M., and McCallum, M.C. "Procedures for investigation and reporting fatigue contributions to marine casualties". Paper presented at the Proceedings of the Human Factors and Ergonmics Society $41^{\text {st }}$ Annual meeting. 1997.

[20] National Transportation Safety Board [NTSB]. Evaluation of US Department of Transportation efforts in the 1990s to address operator fatigue. Washington DC: Author [available online at www.ntsb.gov]. 1999.

[21] Cole-Davies, V. "Fatigue, health and injury offshore: A survey". In M. Hanson (Ed.), Contemporary Ergonomics. London: Taylor \& Francis. 2001.

[22] Parker, A.W., Hubinger, L.M., Green, S., Sargent, L., and Boyd, R. "Health stress and fatigue in shipping". Australian Maritime Safety Agency. 2002.

[23] Hetherington, C., Flin, R., and Mearns, K. "Safety in shipping: The human element". Journal of safety research, 37(4), 2006, pp. 401-411.

[24] Rutenfrantz, J., et al. "Work at Sea: A study of sleep and circadian rhythms in physiological and psychological functions in watchkeepers on merchant vessels". International Archives of Occupational and Environmental Health, 60, 1988, pp. 331-339.

[25] Colquhoun, W.P., Rutenfranz, J., Goethe, H., Neidhart, B., Condone, R., Plett, R., and Knauth, P. "Work at sea: a study of sleep, and of circadian rhythms in physiological and psychological functions, in watchkeepers on merchant vessels". International archives of occupational and environmental health, 60(5), 1988, pp. 321-329.

[26] Sanquist, T.F., Raby, M., Maloney, A.L., and Carvalhais, A.B. "Work Hours, sleep patterns and fatigue among merchant marine personnel". Journal of Sleep Research, 6, 1997, pp. 245-251.

[27] Anthony, R. N. Planning and Control Systems: A Framework for Analysis, Graduate School of Business Administration, Harvad University: Boston. 1965.

[28] Likert R. The Human Organisation: Its management and Value, McGraw - Hill Book Company

[29] Kaplan, R. S. and D.P. Norton Measuring the Strategic Readiness of Intangible Assets, Harvard Business Review (February), 2004, pp. 52-63.

[30] Kaplan, R. S. and D.P. Norton The Balanced Scorecard: Measures that Drive Performance, Harvard Business Review, (January-February), 1992, pp. 71-79. 